\title{
Amputation of a type II diabetic patient with cutaneous leishmaniasis due to Leishmania major
}

\author{
Arezki Izri ${ }^{1,2 \dagger}$, Amina Bendjaballah-Laliam ${ }^{3 \dagger}$, Denis Sereno ${ }^{4,5}$, Ihcene Kherachi Djenad ${ }^{6}$, Zoubir Harrat $^{6}$ and \\ Mohammad Akhoundi ${ }^{*}$ (B)
}

\begin{abstract}
Background: Leishmaniases are neglected tropical diseases of public health concern in Algeria. The immunocompromised patients with HIV, autoimmune diseases, or chronic alcohol abuse are at a higher risk of leishmaniasis. Herein, we present the case of an immunocompetent diabetic patient infected by Leishmania major, leading to lifethreatening consequences.
\end{abstract}

Case presentation: An Algerian diabetic patient developed a cutaneous lesion with large polymorphous inflamed granuloma and pyoderma gangrenosum in the left foot, following L. major infection. A delayed follow-up led to a treatment failure, resulting in the amputation.

Conclusions: This report highlights the absence of timely treatment of Leishmania infection as a life-threatening point among high-risk diabetic patients. Clinicians should be aware of this parasitosis leading to severe complications in diabetic patients.

Keywords: Zoonotic cutaneous leishmaniasis, Leishmania major, Diabetes mellitus, Amputation

\section{Background}

Leishmaniases are vector-borne diseases caused by obligate protozoan parasites from the Leishmania genus (Trypanosomatida: Trypanosomatidae). They are transmitted by the bite of infected female sandflies where the vertebrates like canids, rodents, bats, and hyraxes are reservoirs. Up to the present, 54 Leishmania species are known, with at least 21 human pathogenic ones [1].

Visceral (VL), cutaneous (CL), diffuse cutaneous (DCL), mucocutaneous (MCL), mucosal (ML), and post-kala-azar dermal leishmaniasis (PKDL) are clinical

\footnotetext{
*Correspondence: m.akhoundi@yahoo.com

${ }^{\dagger}$ Arezki Izri and Amina Bendjaballah-Laliam contributed equally to this work

${ }^{1}$ Parasitology-Mycology Department, Avicenne Hospital, AP-HP, 125

Route de Stalingrad, Bobigny Cedex 93009, France

Full list of author information is available at the end of the article
}

forms following Leishmania infections [2]. Ten countries (Afghanistan, Algeria, Colombia, Brazil, Iran, Syria, Ethiopia, North Sudan, Costa Rica, and Peru) encompass $75 \%$ of global CL incidence. Visceral leishmaniasis is highly endemic in six countries: India, Bangladesh, Sudan, South Sudan, Brazil, and Ethiopia [3]. In Algeria, a gradual increase in CL has been recorded over 30 years and ranks it among the most affected countries, with over 20,000 cases every year, making leishmaniasis a significant public health concern [3, 4]. Zoonotic cutaneous leishmaniasis (ZCL), caused by L. major, is prevalent in arid and semi-arid areas over the North Saharan fringe. Anthroponotic cutaneous leishmaniasis (ACL), caused by L. killicki (syn: L. tropica), is restricted to some foci located mainly in Constantine, Annaba, Ghardaia, and Tipaza [5]. Visceral leishmaniasis (VL), caused by L. infantum, is prevalent all over the coastal regions in

(c) The Author(s) 2021. Open Access This article is licensed under a Creative Commons Attribution 4.0 International License, which permits use, sharing, adaptation, distribution and reproduction in any medium or format, as long as you give appropriate credit to the original author(s) and the source, provide a link to the Creative Commons licence, and indicate if changes were made. The images or other third party material in this article are included in the article's Creative Commons licence, unless indicated otherwise in a credit line to the material. If material is not included in the article's Creative Commons licence and your intended use is not permitted by statutory regulation or exceeds the permitted use, you will need to obtain permission directly from the copyright holder. To view a copy of this licence, visit http://creativecommons.org/licenses/by/4.0/. The Creative Commons Public Domain Dedication waiver (http://creativeco mmons.org/publicdomain/zero/1.0/) applies to the data made available in this article, unless otherwise stated in a credit line to the data. 
northwestern Algeria (Oran, Tlemcen), in the Algerian Tell (Tizi-Ouzou, Bouira, Bord Menail, Tipaza, Blida, and Algiers), and the extreme south of the country (Hoggar) $[6,7]$.

\section{Case presentation}

A 49-year-old man was referred in March 2018 to Hadjout public hospital ( $80 \mathrm{~km}$ west of Algiers, Algeria) for a suspected cutaneous fungal infection. He was a primary school guardian who lived in a village in Chlef, $200 \mathrm{~km}$ far from Algiers. The primitive clinical examinations revealed a brownish ulcer, $10 \mathrm{~cm}$ diameter, and $0.3 \mathrm{~cm}$ depth, with a congestive necrotic border under epidermis on the left heel's posterior surface, progressed during 10 months (Fig. 1). The patient was diagnosed diabetic one year ago and suffered from white coat syndrome without regular medical follow-up. There was no notion of maternally inherited disorders or injury due to unexplained causes. Additionally, no notion of smoking, obesity, or AIDS was recorded for this patient. Skin examination revealed the presence of papules with a swelling in the left foot. According to the patient, the cutaneous lesion was initiated in June 2017 by a small insect-bite-like red spot.

Blood analysis revealed a high glycated hemoglobin level (7.8\%, compared to $4-6 \%$ of normal hemoglobin). The histopathological examination showed deep ulceration of the left foot with a large polymorphous inflamed granuloma compatible with pyoderma gangrenosum. No structures suggestive of Leishmania were observed in the histopathological examination. A bone demineralization

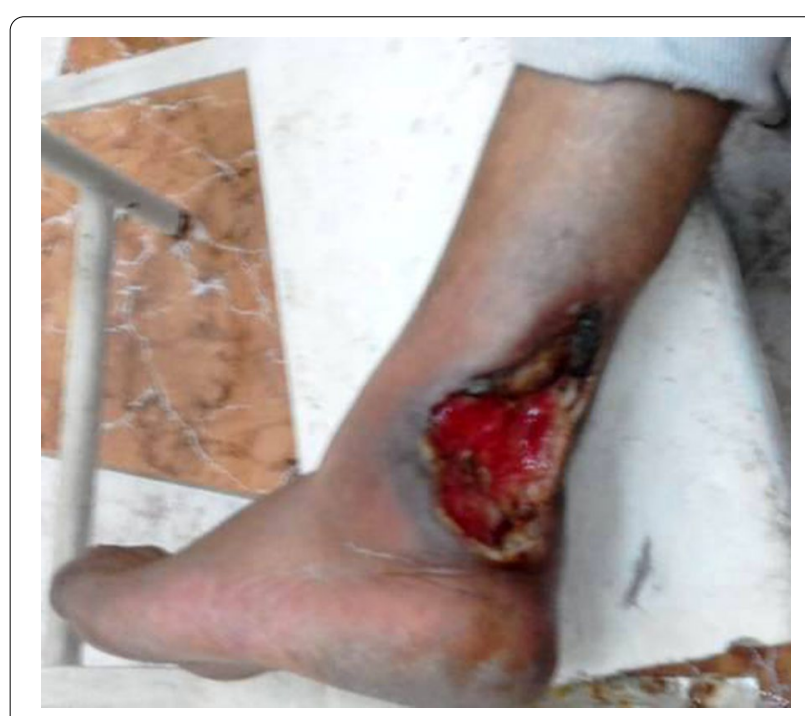

Fig. 1 Extended ulcerative lesion with raised necrotic borders deforming upper part of left foot heel in an Algerian diabetic patient infected by L. major with multiple small lacunar images involving the foot bones with an infectious origin was reported by radiography. There was necrosis in the ankle's posterior soft parts with no notion of joint damage.

Three swabs were prepared from the patient's lesion for mycological, bacteriological, and parasitological examinations. An etiological investigation revealed no fungal infection after direct examination or culture. The bacteriological examination demonstrated bacilliform bacteria, further identified as Klebsiella pneumoniae in differential media. Initial parasitological examination of the Giemsa-stained smear prepared from the patient's lesion revealed no Leishmania infection by microscopy. On the contrary, DNA extraction of the Giemsa-stained smear and bidirectional sequencing of the ITS1-rDNA fragment amplification using conventional PCR [8], revealed the infection by $L$. major. The sequence was deposited in GenBank under the accession number XN348136.

The patient underwent an initial antibiotic therapy by oral pyostacine ( $3 \mathrm{~g} /$ day) for 10 days, leading to the elimination of bacterial infection one month post-treatment. Regrettably, the patient left the treatment incomplete for 5 months without receiving specific leishmaniasis treatment. This delay led to unfavorable CL lesion evolution and advanced infection culminating in extended wet gangrene, worsened over the time with no other treatment option, necessitating an above-the-knee amputation of his left leg in September 2018.

\section{Discussion and conclusions}

Cutaneous leishmaniasis is a chronic disease in which the cutaneous lesion usually heals spontaneously, even without treatment [9]. The lesions vary in severity (e.g., lesion size), numbers, clinical appearance (e.g., dry or wet lesion), and spontaneous healing duration. The initial clinical manifestation is a slightly itchy red papule on the exposed areas, gradually extending to the surface and infiltrating in-depth, leading to central crusty ulceration, producing a typical lesion called oriental lesion [10]. Several pathogenic and non-pathogenic agents may be the cause of or contribute towards the progression of cutaneous lesions. Diabetes mellitus is a metabolic disease causing a deceptive ulcer in extremes, particularly in progressive stages. The feet of diabetic patients are at risk of developing a broad spectrum of clinical conditions, resulting in several diabetes-related complications. Leishmania parasite is one of the infectious etiologies evoked in a chronic leg ulcer. In case of misdiagnosis or failure in treatment, this chronic ulcer can progress and may lead to life-threatening consequences, like an amputation.

Most unusual and atypical clinical aspects of Leishmania infection are reported in immunodeficient patients [11]. Patients with advanced age, long history of 
diabetes mellitus, and cutaneous affection by pathogenic agents like Leishmania, bacterial or fungal microorganisms present a higher risk of amputation [12]. All mentioned criteria were present in our immunocompetent but high-risk patient. Chlef is a known endemic focus of ZVL (zoonotic visceral leishmaniasis) in Algeria, with $L$. infantum as the causative agent [13]. Unlikely, our patient was infected by $L$. major. Literature review depicts that atypical cutaneous presentation is observed in diabetic Leishmania-infected patients, and in very few cases, amputation is documented $[14,15]$. The coexistence of Leishmania infection in diabetic patients favors the development of severe and extensive bacterial or fungal infections in lower limbs that may lead to amputation in inadequately treated cases.

To reduce diabetic-related mortality and morbidity, it is essential combining diabetes control with lesion treatment using antimicrobial medications that might include anti-leishmanial agents, particularly in patients living in leishmaniasis-endemic areas. The treatment of old-world CL is based on peri/intralesional injections of meglumine antimoniate (glucantime ${ }^{\circledR}$ ), systemic therapy by liposomal amphotericin B, or oral fluconazole, depending on the Leishmania species, number, topography, and extent of lesions [16]. In our patient's case, specialized wound care accompanied by several high-dose antibiotic courses like pyostacine could not prevent the left foot tissue's deterioration, associated with a treatment failure. The latter can be attributed to several factors, including (i) long history of a diabetic trophic disorder responsible for gangrene of left foot, (ii) a superinfection with $L$. major, probably acquired by the bite of an infected sand fly (vector of Leishmania parasites), which have worsened the lesion, (iii) abandoning the treatment with glucantime, the first-line treatment for $\mathrm{CL}$, for 5 months, (iv) an advanced age with a white coat syndrome (the patient suffered from stress and anxiety when encountering a physician, which caused him to refuse following the treatment process), (v) remoteness of the patient's residence from the urban health center, and lack of timely access to proper health care, and (vi) a failure in treatment, due to delayed follow-up, which has led to the amputation of the left foot above the knee. This report highlights the absence of timely treatment of Leishmania infection as a life-threatening point among high-risk individuals (e.g., diabetes, AIDS).

\footnotetext{
Abbreviations

HIV: Human immunodeficiency viruses; AIDS: Acquired immunodeficiency syndrome.
}

Acknowledgements

Not applicable.

\begin{abstract}
Authors' contributions
Conceptualization: $\mathrm{Al}, \mathrm{AB}$ and $\mathrm{MA}$; Methodology: $\mathrm{Al}, \mathrm{AB}, \mathrm{DS}, \mathrm{IK}, \mathrm{ZH}$ and $\mathrm{MA}$; Data curation: Al, AB, DS, IK, ZH and MA; Investigation: Al, AB, DS, IK, ZH and $M A ;$ Writing — Original draft preparation: Al, DS and MA; Writing — Reviewing and Editing: $A B, D S, I K, Z H$ and MA. All authors read and approved the final manuscript.
\end{abstract}

\section{Funding}

This research received no external funding.

Availability of data and materials

Not applicable.

\section{Declarations}

Ethics approval and consent to participate

The study was conducted according to the guidelines of the Declaration of Helsinki, and approved by the Ethics Committee of Avicenne Hospital, France (Project identification code: 95/99/AVC/ESA).

\section{Consent for publication}

Informed written consent was provided and signed by the patient, including the authorization for publishing the clinical information.

\section{Competing interests}

The authors declare that they have no competing interests.

\section{Author details}

1Parasitology-Mycology Department, Avicenne Hospital, AP-HP, 125, Route de Stalingrad, Bobigny Cedex 93009, France. ${ }^{2}$ Unité des Virus Émergents (UVE: Aix-Marseille Univ-IRD 190-Inserm 1207-IHU Méditerranée Infection), Marseille, France. ${ }^{3}$ Etablissement Public Hospitalier de Hadjout, Tipaza, Algérie. ${ }^{4}$ Institut de Recherche Pour le Développement, Montpellier University, MIVEGEC, 34032 Montpellier, France. ${ }^{5}$ Institut de Recherche Pour le Développement, Montpellier University, InterTryp, 34032 Montpellier, France. ${ }^{6}$ Laboratoire d'Eco-épidemiologie Parasitaire et Génétique des Populations, Institute Pasteur of Algeria, Route du Petit Staoueli Dely Brahim, Algiers, Algeria.

Received: 8 June 2021 Accepted: 25 November 2021

Published online: 07 December 2021

\section{References}

1. Akhoundi M, Kuhls K, Cannet A, et al. A historical overview of the classification, evolution, and dispersion of Leishmania Parasites and Sandflies. PLoS Negl Trop Dis. 2016;10:e0004349.

2. Akhoundi M, Downing T, Votýpka J, et al. Leishmania infections: molecular targets and diagnosis. Mol Aspects Med. 2017;57:1-29.

3. Alvar J, Vélez ID, Bern C, et al. Leishmaniasis worldwide and global estimates of its incidence. PLos One. 2012;7:5671.

4. Eddaikra N, Ait-Oudhia K, Kherrachi I, et al. Antimony susceptibility of Leishmania isolates collected over a 30-year period in Algeria. PLoS Negl Trop Dis. 2018;12:e0006310.

5. Izri A, Bendjaballah A, Andriantsoanirina V, et al. Cutaneous leishmaniasis caused by Leishmania killicki, Algeria. Emerg Infect Dis. 2014;20:502-4.

6. Izri A, Bendjaballah-Laliam A, Sereno D, et al. Updates on geographical dispersion of Leishmania parasites causing cutaneous affections in Algeria. Pathogens. 2021;10:267.

7. Benallal K, Gassen B, Bouiba L, et al. Entomological investigation following the resurgence of human visceral leishmaniasis in southern Algeria. Acta Tropica. 2013;128:518-23.

8. Schönian G, Nasereddin A, Dinse N, et al. PCR diagnosis and characterization of Leishmania in local and imported clinical samples. Diag Microbiol Infect. 2003;47:349-58.

9. Markle WH, Makhoul K. Cutaneous leishmaniasis: recognition and treatment. Am Fam Physician. 2004;69:1455-60.

10. Hepburn NC. Cutaneous leishmaniasis: an overview. J Postgrad Med. 2003:49:50-4. 
11. Niksolat F, Tabaripour R, Davoodi L, et al. First Autochthonous Case of Emerged Zoonotic Cutaneous Leishmaniasis in Mazandaran Province, Northern Iran: kDNA-PCR Evidence Base. Infect Disord Drug Targets. 2020;1:19.

12. Santos VP, da Silveira DR, Caffaro RA. Risk factors for primary major amputation in diabetic patients. Sao Paulo Med J. 2006;124:2.

13. Harrat Z, Pratlong F, Belazzoug S, et al. Leishmania infantum and L. major in Algeria. Trans R Soc Trop Med Hyg. 1996;90:625-9.

14. Chiheb S, Oudrhiri L, Zouhair K, et al. Leishmanioses cutanées d'aspect clinique inhabituel chez trois patients diabétiques [Unusual clinical presentation of cutaneous leishmaniasis in three diabetic patients]. Ann Dermatol Venereol. 2012;139:542-5.

15. Ait Si Ali MO, Khelfaoui A, Boudene F, et al. Leishmaniose cutanée zostériforme révélant un diabète de type 2: à propos d'un cas. Annales de Dermatologie et de Vénéréologie. 2017;144:S293.

16. Sundar S, Chakravarty J. An update on pharmacotherapy for leishmaniasis. Expert Opin Pharmacother. 2015;16:237-52.

\section{Publisher's Note}

Springer Nature remains neutral with regard to jurisdictional claims in published maps and institutional affiliations.

- fast, convenient online submission

- thorough peer review by experienced researchers in your field

- rapid publication on acceptance

- support for research data, including large and complex data types

- gold Open Access which fosters wider collaboration and increased citations

- maximum visibility for your research: over $100 \mathrm{M}$ website views per year

At BMC, research is always in progress.

Learn more biomedcentral.com/submissions 